\title{
Desensitization for the prevention of drug hypersensitivity reactions
}

\author{
Sung-Yoon Kang ${ }^{1,{ }^{*}}$, Jeongmin $\mathrm{SeO}^{2,}{ }^{2}$, and Hye-Ryun Kang ${ }^{2,3}$
}

\begin{abstract}
${ }^{1}$ Department of Internal Medicine, Gachon University Gil Medical Center, Incheon; ${ }^{2}$ Department of Internal Medicine, Seoul National University College of Medicine, Seoul; ${ }^{3}$ Institute of Allergy and Clinical Immunology, Seoul National University Medical Research Center, Seoul National University College of Medicine, Seoul, Korea
\end{abstract}

Received : September 24, 2021 Accepted: November 19, 2021

\section{Correspondence to \\ Hye-Ryun Kang, M.D.}

Department of Internal Medicine, Seoul National University Hospital, 101 Daehak-ro, Jongno-gu, Seoul 03080, Korea

Tel: $+82-2-2072-0820$

Fax: +82-2-742-3291

E-mail: helenmed@snu.ac.kr

https://orcid.org/0000-0002-23174201

*These authors contributed equally to this work.
Drug desensitization is the temporary induction of tolerance to a sensitized drug by administering slow increments of the drug, starting from a very small amount to a full therapeutic dose. It can be used as a therapeutic strategy for patients with drug hypersensitivity when no comparable alternatives are available. Desensitization has been recommended for immunoglobulin E (IgE)-mediated immediate hypersensitivity; however, its indications have recently been expanded to include non-IgE-mediated, non-immunological, or delayed T cell-mediated reactions. Currently, the mechanism of desensitization is not fully understood. However, the attenuation of various intracellular signals in target cells is an area of active research, such as high-affinity lgE receptor (FcERI) internalization, anti-drug IgG4 blocking antibody, altered signaling pathways in mast cells and basophils, and reduced $\mathrm{Ca}^{2+}$ influx. Agents commonly requiring desensitization include antineoplastic agents, antibiotics, antituberculous agents, and aspirin/nonsteroidal antiinflammatory drugs. Various desensitization protocols (rapid or slow, multi-bag or one-bag, with different target doses) have been proposed for each drug. An appropriate protocol should be selected with the appropriate concentration, dosage, dosing interval, and route of administration. In addition, the protocol should be adjusted with consideration of the severity of the initial reaction, the characteristics of the drug itself, as well as the frequency, pattern, and degree of breakthrough reactions.

Keywords: Drug hypersensitivity; Desensitization, immunologic; Antineoplastic agents; Anti-bacterial agents; Anti-inflammatory agents, non-steroidal

\section{INTRODUCTION}

Drug hypersensitivity reactions (DHRs) are unexpected adverse effects of medications that clinically resemble allergies and are not related to their pharmacological actions. The clinical manifestations of DHR vary from mild skin reactions to potentially fatal systemic reactions, such as anaphylaxis. These phenotypes are classified as immediate or delayed reactions based on their onset and the occurrence of typical symptoms. Both allergic and non-allergic mechanisms can contribute to the development of DHR; allergic reactions are defined as either drug-specific antibody-mediated or cell-mediated immunological responses [1].
Suspicion is the key to diagnosing DHR. A full allergological workup, including detailed history taking and proper physical examination, helps to define the culprit drug and the pathogenic mechanism involved. Laboratory, skin, and provocation tests can help to confirm the diagnosis. If not addressed promptly, DHR can delay scheduled treatments and prolong hospital stay, and can also pose a significant socioeconomic burden due to its comorbidities and complications.

Once DHR is diagnosed, the culprit drug should be avoided and replaced with alternatives. However, alternative options are often less effective, more toxic, and sometimes unavailable. In this situation, drug desensitization allows the 
reintroduction of culprit drugs to highly sensitized patients in need of first-line therapies. Desensitization is performed by administration of extremely low doses of the culprit drug, below the threshold for induction of a hypersensitivity reaction, followed by a gradual increase in the dose at fixed time intervals, to allow adaptation to a given amount or concentration; this leads to the development of temporary tolerance to the drug, eventually at its full therapeutic dose [2].

This review presents an overview of the concept of drug desensitization, an update on its mechanism, and how it is applied in clinical practice.

\section{HISTORICAL BACKGROUND}

The first instance of drug desensitization was reported in the literature in 1922 by Widal et al. [3] who described nonsteroidal antiinflammatory drug (NSAID)-exacerbated respiratory disease (NERD). Rapid drug desensitization (RDD) was first successfully accomplished in the 1940s during World War II, involving the readministration of penicillin to soldiers who had shown anaphylaxis in response to penicillin $[4,5]$. At present, desensitization is performed for DHR to various drugs, including antineoplastic agents, antibiotics, antituberculous agents, and aspirin/NSAIDs.

\section{IMMUNOLOGICAL MECHANISM}

The desensitization process is known to be antigen-specific, as the level of drug-specific immunoglobulin E (IgE) decreases but the levels of other allergen-specific IgE remain consistent throughout the treatment period [6]. However, the cellular and molecular mechanisms underlying drug desensitization are not yet fully understood. The growing body of clinical knowledge has led to several hypotheses, such as the internalization of high-affinity IgE receptor (FcERI), the generation of anti-drug lgG4 blocking antibodies, alteration of signaling pathways in mast cells and basophils, and reduction of $\mathrm{Ca}^{2+}$ influx [7-11].

Some studies showed that suboptimal doses of drug antigens led to the internalization of antigen/lgE/FcERI complex, thus preventing the activation of mast cells or basophils when the therapeutic dose is administered $[12,13]$. However, other studies showed that suboptimal doses of drug antigens induce remodeling of the mast cell membrane, which prevents antigen/lgE/FcERI complex internalization and the initiation of hypersensitivity reactions $[7,8]$.

The action of allergen-specific lgG4, which blocks the interaction between allergens and IgE, has been well characterized in allergen immunotherapy. IgG4 may play a role in desensitization, as the level of drug-specific lgG4 increases after desensitization [14,15]. However, IgG4 cannot fully explain the immediate development of immune tolerance and the sustained effect of desensitization [16].

Various proteins in the activation signaling pathways can be altered during desensitization. Syk protein, a tyrosine protein kinase that transduces the activation signal of mast cells and basophils, expression is reduced after desensitization, which inhibits the activation of FcERI by binding of $\lg$ E to the sensitized drug $[17,18]$. In addition, during the desensitization process, FcyRll with immunoreceptor tyrosine-based inhibition motif competitively inhibits FceRI and dephosphorylates initial signaling molecules, including Syk, through Src homology 2 domain-containing inositol phosphatase 1 (SHIP1), thus blocking the downstream signal transduction to activate mast cells $[9,19-21]$. Furthermore, the decrease in intracellular $\mathrm{Ca}^{2+}$ ions and their impaired influx by the remodeling of actin filaments also inhibit the degranulation of mast cells $[7,8,12,22]$.

In addition, the role of T cells has been increasingly emphasized. It has been suggested that drug desensitization may lead to attenuation of immunological memory as the degree of DHR and the incidence of breakthrough reactions (BTRs) decrease during the desensitization process [23]. Several cases of successful desensitization for T cell-mediated delayed DHR, such as fixed drug eruptions, have been reported in the literature [24]. The increases of $C D 4^{+} C D 25^{+}$or $\mathrm{CD}^{+}{ }^{+} \mathrm{CD} 25^{+} \mathrm{FOXP3}^{+} \mathrm{T}$ cells expressing regulatory cytokines such as interleukin 10 (IL-10) and IL-35 after desensitization suggest a role of regulatory $T$ cells $[23,25,26]$.

In summary, desensitization induces temporary tolerance to the culprit drug by attenuating various intracellular signals to prevent the activation of immunological responses in target cells, thus enabling the safe reintroduction of the drug [7].

\section{APPLICATION IN CLINICAL PRACTICE}

\section{Overview}

The efficacy of drug desensitization is best understood in 
IgE-mediated immediate hypersensitivity. In addition, it is also effective for nonallergic immediate reactions, such as infusion-related reactions, which directly trigger mast cells to secrete their granules or cytokines [27].

Two categories of desensitization protocols are currently available: RDD and slow drug desensitization (SDD). RDD is recommended for immediate reactions, both allergic and nonallergic. The most widely used RDD protocol is doubling the dosage every 15 minutes until the therapeutic dose is achieved. SDD is recommended for type IV delayed hypersensitivity reactions with $\mathrm{T}$ cell involvement, and can be performed both orally and intravenously. There is as yet no consensus on SDD protocols, including the initial dose, dose increments between steps, and dosing interval. Further clinical experience and research are required to establish the role and efficacy of desensitization for delayed reactions $[28,29]$.

Before performing drug desensitization, the diagnosis should be confirmed by thorough history taking and testing. Desensitization should be considered when no alternative options are available or the culprit drug has far superior efficacy, i.e., the benefits of the culprit drug outweigh the risk. It should be carefully applied in patients with significant risk factors for fatal BTRs, such as those with a history of severe hypersensitivity reactions, like anaphylaxis, Stevens-Johnson syndrome, and toxic epidermal necrolysis, those with cardiovascular or respiratory diseases, and those using beta-blockers. The appropriate protocol should be selected based on the concentration, dosage, dosing interval, and route of administration (oral, intravenous, intramuscular, or subcutaneous). Oral and intravenous protocols are widely used because intramuscular and subcutaneous protocols involve frequent injections. The route of administration can be switched without compromising the efficacy. It is feasible to perform desensitization through intravenous drug administration for meticulous dose adjustment and administer the therapeutic dose in oral form.

$\mathrm{H} 1$ blockers, $\mathrm{H} 2$ blockers, and glucocorticoids can be used as premedication. Aspirin and montelukast block the end products of the arachidonic acid cascade and decrease the incidence and severity of BTRs. NSAIDs can help to control the symptoms of cytokine release syndrome. Glucocorticoids alone are not recommended because they cannot prevent the initial degranulation of mast cells [30].

BTRs should be promptly managed depending on their severity. For mild to moderate BTR, desensitization should be stopped, and appropriate medication, such as antihista- mines and/or glucocorticoids, should be administered to the patient. After the symptoms have resolved, desensitization can be resumed at the same step or the step prior to that in which BTR occurred, and most patients succeed in completing the protocol without further BTRs. In cases of anaphylaxis, intramuscular epinephrine, massive hydration, and proper oxygenation are essential. Desensitization should be stopped until the patient is stabilized, and further desensitization protocols should be tailored by an allergy specialist.

Immunological tolerance can be maintained with continued administration of the drug. For drugs that are administered intermittently, such as chemotherapeutic agents, desensitization should be performed at every cycle, as the tolerance fades during the drug-free interval. If the patient undergoes multiple cycles of desensitization, the number of steps can be gradually tapered unless BTRs occur. However, shortening of the protocol should be performed carefully by a specialist, considering the severity of the initial DHR, the characteristics of the drug itself, as well as the frequency, pattern, and degree of BTR.

\section{Antineoplastic agents}

Antineoplastic agents are repeatedly administered at regular time intervals, which increase the risk of sensitization to these drugs. The incidence of DHR to antineoplastic agents varies according to the type of drug, ranging from $1 \%$ to $80 \%$ [31-33]. The common causative agents include platinum (e.g., cisplatin, carboplatin, and oxaliplatin), taxanes (e.g., paclitaxel and docetaxel), and monoclonal antibodies (e.g., rituximab, infliximab, trastuzumab, bevacizumab, etc.) [34]. DHR is commonly caused by sensitization with drug-specific IgE, which can be confirmed by skin tests [35-38]. However, non-lgE-mediated reactions, such as infusion-related or solvent-related reactions (e.g., cremophor, polysorbate 80), have also been reported in the literature $[32,33,39]$. Mast cell-mediated or basophil-mediated reactions present with urticaria, angioedema, laryngeal edema, vomiting, abdominal pain, or anaphylaxis. On the other hand, cytokine-mediated reactions present with generalized rash, abrupt chest discomfort, dyspnea, back pain, fever, chills, or myalgia.

As mentioned above, the most prevalent causes of DHR include platinum, taxanes, and monoclonal antibodies, which present with different clinical manifestations. DHR to platinum has been reported in $1 \%$ to $44 \%$ of patients [30]. By gradual sensitization after multiple exposures, the first DHR most frequently occurs on the 8th to 9th administration, es- 
Table 1. An example of a 3-bag, 12-step desensitization protocol for rituximab (600 mg)

\begin{tabular}{|c|c|c|c|c|c|}
\hline Step & Concentration, mg/mL & Rate, $\mathrm{mL} / \mathrm{hr}$ & Infusion time, min & Dose, mg & Volume, $\mathrm{mL}$ \\
\hline 1 & 0.012 & 5 & 15 & 0.015 & 1.25 \\
\hline 2 & 0.012 & 10 & 15 & 0.030 & 2.5 \\
\hline 3 & 0.012 & 20 & 15 & 0.060 & 5 \\
\hline 4 & 0.012 & 50 & 15 & 0.150 & 12.5 \\
\hline 5 & 0.012 & 100 & 15 & 0.300 & 25 \\
\hline 6 & 0.12 & 20 & 15 & 0.60 & 5 \\
\hline 7 & 0.12 & 50 & 15 & 1.50 & 12.5 \\
\hline 8 & 0.12 & 100 & 15 & 3.00 & 25 \\
\hline 9 & 1.2 & 20 & 15 & 6 & 5 \\
\hline 10 & 1.2 & 50 & 15 & 15 & 12.5 \\
\hline 11 & 1.2 & 100 & 15 & 30 & 25 \\
\hline 12 & 1.2 & 200 & 135.8 & 543.36 & 452.8 \\
\hline
\end{tabular}

Rituximab $600 \mathrm{mg} / 60 \mathrm{~mL}$ was reconstituted with $440 \mathrm{~mL}$ normal saline. The concentration of the solution was $1.2 \mathrm{mg} / \mathrm{mL}$. Dose $(\mathrm{mg})=$ rate $(\mathrm{mL} / \mathrm{hr}) \times$ time/60 $(\mathrm{hr}) \times$ concentration $(\mathrm{mg} / \mathrm{mL})$.

pecially when it is resumed after a drug-free period. The correlation between skin test positivity and DHR has been well established. As cross-reactivity can occur between platinum agents, care should be taken when switching agents within platinum-based regimens. As BTRs are common even after previous successful desensitization, shortening of the protocol should be adopted gradually and carefully. In contrast, infusion-related reactions to taxanes tend to occur during the first or second administration. In addition, IgE-mediated reactions can occur in some patients who have specific lgE to the pollen of Taxus baccata, a common yew used as a source of taxanes. DHR to taxanes has been reported in $5 \%$ to $10 \%$ of patients. As taxane-associated BTRs usually occur during the initial attempts of desensitization, the number of steps within desensitization protocols can be safely reduced if the BTR does not occur repeatedly during the early cycles of desensitization. Monoclonal antibodies lead to various types of DHR, including lgE-mediated reactions, cytokine release syndrome, and mixed reactions, which can arise in both the earlier and later courses. The rate of DHR varies according to the degree of humanization and glycosylation pattern, and commonly reported agents include rituximab and cetuximab. Especially for cetuximab, the association with anti-a-1,3-galactose IgE has been observed, which is generated from the consumption of animals that were bitten by a specific type of tick [30].

Various desensitization protocols have been proposed for antineoplastic agents. A protocol from the Adverse Drug Reaction and Desensitization Program in Brigham and Women's Hospital has been well established worldwide (Table 1) [36]. In this protocol, the culprit drug solution (1:1) is diluted to $1: 10,1: 100$, and sometimes $1: 1,000$, and the concentration and rate of administration is escalated stepwise for 15 minutes. This multi-bag protocol is completed in most patients without serious BTR [40-42]. However, multi-bag protocols require excessive time and effort for dilution and changing bags, and increase the risk of exposure of medical staff to antineoplastic agents in the process. In addition, the stability of the drug can be compromised by dilution and administration for a prolonged period.

To overcome these shortcomings, a one-bag protocol was proposed in which a single concentration was used and only the rate of administration was increased (Table 2) [43-46]. Successful completion of desensitization with a one-bag protocol has been reported for all platinum, taxane, and monoclonal antibodies. There were no statistically significant differences regarding the rate of completion or the incidence of BTRs compared to multi-bag methods, while the amount of time required for the preparation was significantly reduced. In addition, the incidence of BTR decreased in the later course of treatment, which was consistent with multi-bag protocols [43-46]. Therefore, it is anticipated that the one-bag protocol can replace the multiple-bag protocol, thus reducing time and effort, maintaining the stability 
Table 2. An example of a 1-bag, 12-step desensitization protocol for rituximab (600 mg)

\begin{tabular}{lccccc}
\hline Step & Concentration, $\mathrm{mg} / \mathrm{mL}$ & Rate, $\mathrm{mL} / \mathrm{hr}$ & Time, $\mathrm{min}$ & Dose, $\mathrm{mg}$ & Volume, $\mathrm{mL}$ \\
\hline 1 & 2.857 & 0.1 & 15 & 0.1 & 0.025 \\
2 & 2.857 & 0.2 & 15 & 0.1 & 0.05 \\
3 & 2.857 & 0.4 & 15 & 0.3 & 0.1 \\
4 & 2.857 & 0.8 & 15 & 0.6 & 0.2 \\
5 & 2.857 & 1.6 & 15 & 1.1 & 0.4 \\
6 & 2.857 & 3 & 15 & 2.1 & 0.75 \\
\hline 7 & 2.857 & 6 & 15 & 4.3 & 1.5 \\
8 & 2.857 & 12.5 & 15 & 8.9 & 3.125 \\
9 & 2.857 & 25 & 15 & 17.9 & 6.25 \\
10 & 2.857 & 50 & 15 & 35.7 & 12.5 \\
11 & 2.857 & 100 & 15 & 71.4 & 25 \\
\hline 12 & 2.857 & 150 & 64.04 & 457.4 & 160.1 \\
\hline
\end{tabular}

Rituximab $600 \mathrm{mg} / 60 \mathrm{~mL}$ was reconstituted with $150 \mathrm{~mL}$ of normal saline. The concentration of the solution was $2.85714 \mathrm{mg} / \mathrm{mL}$. Dose $(\mathrm{mg})=$ rate $(\mathrm{mL} / \mathrm{hr}) \times$ time $/ 60(\mathrm{hr}) \times$ concentration $(\mathrm{mg} / \mathrm{mL})$.

of the agents, preventing erroneous dilutions, and reducing the risk of exposure of medical staff to antineoplastic agents.

In addition, the efficacy of chemotherapy is unlikely to be compromised by desensitization. Sloane et al. [42] conducted a large retrospective analysis of patients with recurrent ovarian cancer who underwent RDD for carboplatin; overall survival in the RDD group was non-inferior to that of the regular administration group.

\section{Antibiotics}

DHR to $\beta$-lactams, such as penicillin or cephalosporin, is more common than that to non- $\beta$-lactams. Desensitization can be performed for both immediate and delayed hypersensitivity reactions. The protocol should be selected based on patient characteristics, hospital capacity, and physician preferences. It is generally started with 1/1,000 of the therapeutic dose and then increased by 2 to 3 -fold every 15 minutes to 5 hours. Oral administration is preferred due to its ease, safety, and effectiveness [47]. Desensitization to penicillin and cephalosporins has been well established. Successful desensitization has also been reported for other $\beta$-lactams, such as carbapenem and monobactam, and non- $\beta$-lactams, such as vancomycin, clindamycin, metronidazole, macrolides, aminoglycosides, tetracycline, and ciprofloxacin [48-58].

Red man syndrome (RMS) is a distinctive hypersensitivity reaction to vancomycin, ciprofloxacin, teicoplanin, or am- photericin; it is caused by the direct activation of mast cells and secretion of histamine, and is associated with the rate of administration [59]. It can usually be prevented by reducing the rate of administration and pretreating patients with antihistamines. However, in cases of moderate-to-severe RMS, the desensitization protocol can be applied in the absence of appropriate alternative agents. Both RDD and SDD have been studied for RMS; in most cases, RDD can be applied first and, in the case of failure, the protocol can be switched to SDD $[60,61]$.

Successful desensitization to other antimicrobials has also been reported for antifungals, such as amphotericin B, fluconazole, itraconazole, voriconazole, and micafungin, and for antivirals, such as acyclovir, valganciclovir, ribavirin, and nevirapine [62-69].

\section{Antituberculous agents}

Tuberculosis possesses unique microbial characteristics that require prolonged simultaneous administration of multiple agents. DHR to antituberculous agents is reported in $4 \%$ to $5 \%$ of patients, which leads to the discontinuation or alteration of medications or prolonged treatment duration [70]. It is common for patients with tuberculosis to be hypersensitive to one or two agents, and delayed reactions, such as maculopapular rash, are more prevalent than immediate reactions, such as urticaria or angioedema [71].

Successful cases of desensitization to antituberculous 
Table 3. An example of isoniazid desensitization protocol (target dose: $\mathbf{3 0 0} \mathrm{mg}$ )

\begin{tabular}{|c|c|c|c|c|c|}
\hline Step & & Concentration, $\mathrm{mg} / \mathrm{mL}$ & Volume, $\mathrm{mL}$ & Time interval between doses, $\mathrm{hr}$ & Administered dose, $\mathrm{mg}$ \\
\hline \multirow[t]{8}{*}{ Day 1} & 1 & 0.2 & 0.1 & & 0.02 \\
\hline & 2 & 0.2 & 0.2 & 2 & 0.04 \\
\hline & 3 & 0.2 & 0.5 & 2 & 0.1 \\
\hline & 4 & 0.2 & 1 & 2 & 0.2 \\
\hline & 5 & 0.2 & 2 & 2 & 0.4 \\
\hline & 6 & 0.2 & 4 & 2 & 0.8 \\
\hline & 7 & 0.2 & 8 & 2 & 1.6 \\
\hline & 8 & 0.2 & 16 & 2 & 3.2 \\
\hline \multirow[t]{6}{*}{ Day 2} & 9 & 2.0 & 3 & & 6 \\
\hline & 10 & 2.0 & 6 & 2 & 12 \\
\hline & 11 & 2.0 & 12 & 2 & 24 \\
\hline & 12 & 100 mg Tab & $0.5 \mathrm{Tab}$ & 2 & 50 \\
\hline & 13 & 100 mg Tab & $1 \mathrm{Tab}$ & 2 & 100 \\
\hline & 14 & 100 mg Tab & $2 \mathrm{Tab}$ & 2 & 200 \\
\hline Day 3 & 15 & 100 mg Tab & $3 \mathrm{Tab}$ & & 300 \\
\hline
\end{tabular}

agents, both oral and intravenous, have been reported in the literature since 1990. Through desensitization, 60\% to $80 \%$ of patients who were hypersensitive to first-line antituberculous agents could continue therapy with those drugs (Table 3) [72]. In addition, second-line agents, such as streptomycin, kanamycin, and cycloserine, have also been continued safely with intramuscular, intravenous, and oral desensitization protocols [73]. In a Korean multicenter study of patients with severe cutaneous adverse reactions to antituberculous agents, the replacement of all drugs did not prevent the recurrence of DHR, possibly due to the development of multi-drug hypersensitivity after drug reaction with eosinophilia and systemic symptoms [74]. However, 84.6\% of patients undergoing desensitization succeeded in continuing the original drugs, and their BTRs were no greater than mild.

Both RDD and SDD were studied at intervals of 15 minutes to 1 hour for RDD and a few hours to a day for SDD [75]. RDD has strengths in patient compliance and medication resistance, while SDD has better success rates and safety $[29,72,76]$. SDD has been recommended for delayed DHR; however, multiple successful RDDs for delayed reactions have also been reported [29].

\section{Aspirin and NSAIDs}

Hypersensitivity reactions to aspirin/NSAIDs can have varying manifestations, depending on the onset of symptoms and the organs involved [77]. Various protocols for aspirin/ NSAIDs, which are adapted from aspirin provocation test protocols, have been suggested [3,78-82]. The mechanism of aspirin/NSAID hypersensitivity is still not fully understood, but non-immunological mechanisms of cyclooxygenase (COX) inhibition are the most plausible. The desensitization process downregulates the production of cysteinyl leukotriene and its receptors, attenuating skin and airway responses [83].

Aspirin/NSAID desensitization is considered for patients with cardiovascular or musculoskeletal diseases who require aspirin or NSAID administration for prolonged periods. It is also considered for patients with aspirin/NERD to improve the overall symptoms and quality of life, and decrease the formation of nasal polyps and sinus infections; however, the effects on asthma outcomes are less consistent [84].

Oral desensitization protocols for aspirin are well established. Notably, the therapeutic dose at the final step differs according to the indication for aspirin/NSAIDs. For cardiovascular or musculoskeletal diseases, a lower dose of aspirin (75 to $100 \mathrm{mg} /$ day) is used. In contrast, for aspirin-exacerbated respiratory disease or chronic sinusitis with or without 
Table 4. An example of aspirin desensitization protocol proposed by Silberman et al. and the EAACl guidelines (target dose: 100 and $325 \mathrm{mg}$ )

\begin{tabular}{|c|c|c|c|c|}
\hline \multicolumn{5}{|c|}{ Dose of aspirin, mg } \\
\hline \multicolumn{2}{|c|}{ Cardiovascular or musculoskeletal diseases } & \multicolumn{3}{|c|}{ Aspirin-exacerbated respiratory disease or chronic sinusitis with or without nasal polyps } \\
\hline Dosing interval, min & Day 1 & Dosing interval, $\mathrm{hr}$ & Day 1 & Day 2 \\
\hline & $1 \mathrm{mg}$ & & $20-40 \mathrm{mg}$ & $100-160 \mathrm{mg}$ \\
\hline 30 & $2 \mathrm{mg}$ & & & \\
\hline 30 & $4 \mathrm{mg}$ & & & \\
\hline 30 & $8 \mathrm{mg}$ & 2 & $40-60 \mathrm{mg}$ & $160-325 \mathrm{mg}$ \\
\hline 30 & $16 \mathrm{mg}$ & & & \\
\hline 30 & $32 \mathrm{mg}$ & & & \\
\hline 30 & $64 \mathrm{mg}$ & 2 & $60-100 \mathrm{mg}$ & 325 mg \\
\hline 30 & 100 mg & & & \\
\hline
\end{tabular}

EAACl, the European Academy of Allergy and Clinical Immunology.

nasal polyps, a higher dose of aspirin (up to $625 \mathrm{mg} /$ day) is administered (Table 4) [84].

For DHR to NSAIDs other than aspirin, it is recommended to switch to drugs that have little COX-1 inhibitory effect (e.g., acetaminophen), drugs that exhibit relatively selective COX-2 inhibition (e.g., nimesulide and meloxicam), or drugs that are highly selective COX-2 inhibitors (e.g., celecoxib and etoricoxib) if well tolerated. The desensitization protocol for NSAIDs can be modified from that for aspirin [77]. The temporary tolerance to aspirin/NSAIDs lasts 48 to 72 hours after desensitization. Therefore, hypersensitivity reactions can recur 2 to 5 days after discontinuation if the therapeutic dose is not continued $[85,86]$.

\section{CONCLUSIONS}

Here, we discussed the mechanism of desensitization and its actual implementation for antineoplastic agents, antibiotics, antituberculous agents, and aspirin/NSAIDs. The development of hypersensitivity following repetitive administration of drugs is a major impediment to treatment. Desensitization induces temporary tolerance to the drug by gradually incrementing the dose to reach the therapeutic dose. Drug desensitization should be considered when the benefits of the culprit drug outweigh the risk. However, it should be applied carefully in patients with significant risk factors for fa- tal BTRs, such as those with a history of severe hypersensitivity reactions. In the desensitization procedure, various BTRS ranging from mild to severe can occur, but most resolve if desensitization is stopped immediately. Further research regarding the mechanism of desensitization and optimal protocols for different medications is warranted.

\section{Conflict of interest}

No potential conflict of interest relevant to this article was reported.

\section{REFERENCES}

1. Demoly $\mathrm{P}$, Adkinson NF, Brockow K, et al. International consensus on drug allergy. Allergy 2014;69:420-437.

2. Mezzano V, Giavina-Bianchi P, Picard M, Caiado J, Castells M. Drug desensitization in the management of hypersensitivity reactions to monoclonal antibodies and chemotherapy. BioDrugs 2014;28:133-144.

3. Widal F, Abrami P, Lermoyez J. Anaphylaxis and idiosyncrasy. 1992. Allergy Proc 1993;14:373-376.

4. Peck SM, Siegal S, Bergamini R. Successful desensitization in penicillin sensitivity. J Am Med Assoc 1947;134:1546.

5. O'Donovan WJ, Klorfajn I. Sensitivity to penicillin: anaphylaxis and desensitisation. Lancet 1946;2:444-446.

6. Vultaggio A, Nencini F, Bormioli S, et al. Desensitization mod- 
ulates humoral and cellular immune response to infliximab in a patient with an immediate hypersensitivity reaction. J Allergy Clin Immunol Pract 2020;8:1764-1767.

7. Ang WX, Church AM, Kulis M, Choi HW, Burks AW, Abraham SN. Mast cell desensitization inhibits calcium flux and aberrantly remodels actin. J Clin Invest 2016;126:4103-4118.

8. Sancho-Serra Mdel C, Simarro M, Castells M. Rapid IgE desensitization is antigen specific and impairs early and late mast cell responses targeting FceRI internalization. Eur J Immunol 2011;41:1004-1013.

9. Mahajan A, Barua D, Cutler $P$, et al. Optimal aggregation of FcERI with a structurally defined trivalent ligand overrides negative regulation driven by phosphatases. ACS Chem Biol 2014;9:1508-1519.

10. Shalit M, Levi-Schaffer F. Challenge of mast cells with increasing amounts of antigen induces desensitization. Clin Exp Allergy 1995;25:896-902.

11. Andrews NL, Pfeiffer JR, Martinez AM, et al. Small, mobile FcepsilonRI receptor aggregates are signaling competent. Immunity 2009;31:469-479.

12. Oka T, Rios EJ, Tsai M, Kalesnikoff J, Galli SJ. Rapid desensitization induces internalization of antigen-specific lgE on mouse mast cells. J Allergy Clin Immunol 2013;132:922-932.

13. Paolini R, Numerof $R$, Kinet JP. Phosphorylation/dephosphorylation of high-affinity IgE receptors: a mechanism for coupling/uncoupling a large signaling complex. Proc Natl Acad Sci U S A 1992;89:10733-10737.

14. Naclerio R, Mizrahi EA, Adkinson NF Jr. Immunologic observations during desensitization and maintenance of clinical tolerance to penicillin. J Allergy Clin Immunol 1983;71:294-301.

15. Shamji MH, Kappen J, Abubakar-Waziri $\mathrm{H}$, et al. Nasal allergen-neutralizing IgG4 antibodies block IgE-mediated responses: novel biomarker of subcutaneous grass pollen immunotherapy. J Allergy Clin Immunol 2019;143:1067-1076.

16. Shakir EM, Cheung DS, Grayson MH. Mechanisms of immunotherapy: a historical perspective. Ann Allergy Asthma Immunol 2010;105:340-347.

17. Macglashan D, Miura K. Loss of syk kinase during lgE-mediated stimulation of human basophils. J Allergy Clin Immunol 2004;114:1317-1324.

18. Odom S, Gomez G, Kovarova M, et al. Negative regulation of immunoglobulin E-dependent allergic responses by Lyn kinase. J Exp Med 2004;199:1491-1502.

19. Katz HR. Inhibitory receptors and allergy. Curr Opin Immunol 2002;14:698-704.

20. Katz HR. Inhibition of anaphylactic inflammation by the
gp49B1 receptor on mast cells. Mol Immunol 2002;38:13011305.

21. Lu-Kuo JM, Joyal DM, Austen KF, Katz HR. gp49B1 inhibits IgE-initiated mast cell activation through both immunoreceptor tyrosine-based inhibitory motifs, recruitment of src homology 2 domain-containing phosphatase-1, and suppression of early and late calcium mobilization. J Biol Chem 1999;274:5791-5796.

22. Folkerts J, Stadhouders R, Redegeld FA, et al. Effect of dietary fiber and metabolites on mast cell activation and mast cell-associated diseases. Front Immunol 2018;9:1067.

23. Vultaggio A, Matucci A, Nencini F, Bormioli S, Vivarelli E, Maggi $E$. Mechanisms of drug desensitization: not only mast cells. Front Pharmacol 2020;11:590991.

24. Teraki $Y$, Shiohara T. Successful desensitization to fixed drug eruption: the presence of CD25+CD4+ T cells in the epidermis of fixed drug eruption lesions may be involved in the induction of desensitization. Dermatology 2004;209:29-32.

25. Aydogan M, Yologlu N, Gacar G, Uyan ZS, Eser I, Karaoz E. Successful rapid rituximab desensitization in an adolescent patient with nephrotic syndrome: increase in number of Treg cells after desensitization. J Allergy Clin Immunol 2013;132:478-480.

26. Tuzer C, Sari M, Aktas Cetin E, et al. Rapid drug desensitization for platinum-based chemotherapy drugs significantly increases peripheral blood IL-10 levels. Allergy 2020;75:29422945.

27. Hong DI. Desensitization for allergic reactions to chemotherapy. Yonsei Med J 2019;60:119-125.

28. Siripassorn K, Ruxrungtham K, Manosuthi W. Successful drug desensitization in patients with delayed-type allergic reactions to anti-tuberculosis drugs. Int J Infect Dis 2018;68:61-68.

29. Ban GY, Jeong YJ, Lee SH, et al. Efficacy and tolerability of desensitization in the treatment of delayed drug hypersensitivities to anti-tuberculosis medications. Respir Med 2019;147:44-50.

30. Caiado J, Castells MC. Drug desensitizations for chemotherapy: safety and efficacy in preventing anaphylaxis. Curr Allergy Asthma Rep 2021;21:37.

31. Markman M, Kennedy A, Webster K, et al. Clinical features of hypersensitivity reactions to carboplatin. J Clin Oncol 1999;17:1141.

32. Weiss RB, Donehower RC, Wiernik PH, et al. Hypersensitivity reactions from taxol. J Clin Oncol 1990;8:1263-1268.

33. Markman M, Kennedy A, Webster K, Kulp B, Peterson G, Belinson J. Paclitaxel-associated hypersensitivity reactions: expe- 
rience of the gynecologic oncology program of the Cleveland Clinic Cancer Center. J Clin Oncol 2000;18:102-105.

34. Lee SY, Yang MS, Jung JW, et al. Updates on desensitization for hypersensitivity reactions related to chemotherapy. Allergy Asthma Respir Dis 2013;1:295-302.

35. Cortijo-Cascajares S, Nacle-Lopez I, Garcia-Escobar I, et al. Effectiveness of oxaliplatin desensitization protocols. Clin Transl Oncol 2013;15:219-225.

36. Lee CW, Matulonis UA, Castells MC. Carboplatin hypersensitivity: a 6-h 12-step protocol effective in 35 desensitizations in patients with gynecological malignancies and mast cell/ IgE-mediated reactions. Gynecol Oncol 2004;95:370-376.

37. Lee CW, Matulonis UA, Castells MC. Rapid inpatient/outpatient desensitization for chemotherapy hypersensitivity: standard protocol effective in 57 patients for 255 courses. Gynecol Oncol 2005;99:393-399.

38. Lax T, Long A, Banerji A. Skin testing in the evaluation and management of carboplatin-related hypersensitivity reactions. J Allergy Clin Immunol Pract 2015;3:856-862.

39. Dye $D$, Watkins J. Suspected anaphylactic reaction to Cremophor EL. Br Med J 1980;280:1353.

40. Castells MC, Tennant NM, Sloane DE, et al. Hypersensitivity reactions to chemotherapy: outcomes and safety of rapid desensitization in $\mathbf{4 1 3}$ cases. J Allergy Clin Immunol 2008; 122:574-580.

41. Feldweg AM, Lee CW, Matulonis UA, Castells M. Rapid desensitization for hypersensitivity reactions to paclitaxel and docetaxel: a new standard protocol used in 77 successful treatments. Gynecol Oncol 2005;96:824-829.

42. Sloane D, Govindarajulu U, Harrow-Mortelliti J, et al. Safety, costs, and efficacy of rapid drug desensitizations to chemotherapy and monoclonal antibodies. J Allergy Clin Immunol Pract 2016;4:497-504.

43. Lee JH, Moon M, Kim YC, et al. A one-bag rapid desensitization protocol for paclitaxel hypersensitivity: a noninferior alternative to a multi-bag rapid desensitization protocol. J Allergy Clin Immunol Pract 2020;8:696-703.

44. Chung SJ, Kang SY, Kang RY, et al. A new non-dilution rapid desensitization protocol successfully applied to all-grade platinum hypersensitivity. Cancer Chemother Pharmacol 2018:82:777-785.

45. Kim HH, Moon M, Cho MK, et al. Comparison of one-bag and multibag desensitization protocols for the prevention of rituximab hypersensitivity. Allergy Asthma Respir Dis 2020;8:135-141.

46. Lee $\mathrm{SH}$, Lee $\mathrm{JH}, \mathrm{Kim} \mathrm{NH}$, et al. A case of rapid desensitization for rituximab-induced delayed hypersensitivity reaction. Allergy Asthma Respir Dis 2019;7:109-112.

47. Cernadas JR, Brockow K, Romano A, et al. General considerations on rapid desensitization for drug hypersensitivity: a consensus statement. Allergy 2010;65:1357-1366.

48. Stark BJ, Earl HS, Gross GN, Lumry WR, Goodman EL, Sullivan TJ. Acute and chronic desensitization of penicillin-allergic patients using oral penicillin. J Allergy Clin Immunol 1987;79:523-532.

49. Wendel GD Jr, Stark BJ, Jamison RB, Molina RD, Sullivan TJ. Penicillin allergy and desensitization in serious infections during pregnancy. N Engl J Med 1985;312:1229-1232.

50. Ghosal S, Taylor CJ. Intravenous desensitization to ceftazidime in cystic fibrosis patients. J Antimicrob Chemother 1997;39:556-557.

51. Papakonstantinou G, Bogner JR, Hofmeister F, Hehlmann R. Cefotaxime desensitization. Clin Investig 1993;71:165-167.

52. Win PH, Brown H, Zankar A, Ballas ZK, Hussain I. Rapid intravenous cephalosporin desensitization. J Allergy Clin Immunol 2005; 116:225-228.

53. Wilson DL, Owens RC Jr, Zuckerman JB. Successful meropenem desensitization in a patient with cystic fibrosis. Ann Pharmacother 2003;37:1424-1428.

54. Marcos C, Sopena B, Luna I, Gonzalez R, de la Fuente J, Martinez-Vazquez C. Clindamycin desensitization in an AIDS patient. AIDS 1995;9:1201-1202.

55. Swamy N, Laurie SA, Ruiz-Huidobro E, Khan DA. Successful clarithromycin desensitization in a multiple macrolide-allergic patient. Ann Allergy Asthma Immunol 2010;105:489-490.

56. Earl HS, Sullivan TJ. Acute desensitization of a patient with cystic fibrosis allergic to both beta-lactam and aminoglycoside antibiotics. J Allergy Clin Immunol 1987;79:477-483.

57. Fernando SL, Hudson BJ. Rapid desensitization to doxycycline. Ann Allergy Asthma Immunol 2013;111:73-74.

58. Gea-Banacloche JC, Metcalfe DD. Ciprofloxacin desensitization. J Allergy Clin Immunol 1996;97:1426-1427.

59. Lin RY. Desensitization in the management of vancomycin hypersensitivity. Arch Intern Med 1990;150:2197-2198.

60. Anne S, Middleton E Jr, Reisman RE. Vancomycin anaphylaxis and successful desensitization. Ann Allergy 1994;73:402-404.

61. Lerner A, Dwyer JM. Desensitization to vancomycin. Ann Intern Med 1984;100:157.

62. Shadur B, Trahair TN, O'Brien T, Russell SJ, Ziegler JB. Desensitisation to liposomal amphotericin B. J Allergy Clin Immunol Pract 2017;5:181-183.

63. Randolph C, Kaplan C, Fraser B. Rapid desensitization 
to fluconazole (Diflucan). Ann Allergy Asthma Immunol 2008; 100:616-617.

64. Douglas R, Spelman D, Czarny D, O'Hehir R. Desensitization to itraconazole. J Allergy Clin Immunol 1997;99:269.

65. Jean T, Kwong K. Successful desensitization of voriconazole in an immunosuppressed pediatric patient. J Allergy Clin Immunol Pract 2015;3:637-638.

66. Seki JT, Ng P, Lam W, Cote J, Prica A. Recurrent body rash warranted second desensitization with acyclovir in a myeloma patient: a case report. J Clin Med Res 2017;9:725-728.

67. Gonzalez-Estrada A, Fernandez J. Novel valganciclovir desensitization protocol. Transplantation 2014;98:e50-e51.

68. Ladd AM, Martel-Laferriere V, Dieterich D. Successful desensitization to ribavirin in a patient with chronic hepatitis $C$. J Clin Gastroenterol 2012;46:716-717.

69. Heo YJ, Park SW, Lee KS, Kang HR, Kwon JW. Successful desensitization to fluconazole induced delayed hypersensitivity: a case report. Allergy Asthma Respir Dis 2018;6:68-71.

70. Park JS. Korean guidelines for the treatment of tuberculosis. Korean J Med 2012;82:269-273.

71. Thong BY. Update on the management of antibiotic allergy. Allergy Asthma Immunol Res 2010;2:77-86.

72. Kobashi Y, Abe T, Shigeto E, Yano S, Kuraoka T, Oka M. Desensitization therapy for allergic reactions to antituberculous drugs. Intern Med 2010;49:2297-2301.

73. Moon SD, Won HK, Cho JY, et al. Successful readministration of second-line antituberculous agents in a patient with near-fatal drug reaction with eosinophilia and systemic symptoms (DRESS) syndrome. Allergy Asthma Respir Dis 2015;3:297-301.

74. Oh JH, Yun J, Yang MS, et al. Reintroduction of antituberculous drugs in patients with antituberculous drug-related drug reaction with eosinophilia and systemic symptoms. J Allergy Clin Immunol Pract 2021;9:3442-3449.

75. Holland CL, Malasky C, Ogunkoya A, Bielory L. Rapid oral de- sensitization to isoniazid and rifampin. Chest 1990;98:15181519.

76. Thong BY, Chia FL, Tan SC, et al. A retrospective study on sequential desensitization-rechallenge for antituberculosis drug allergy. Asia Pac Allergy 2014;4:156-163.

77. Yeung WY, Park HS. Update on the management of nonsteroidal anti-inflammatory drug hypersensitivity. Yonsei Med J 2020;61:4-14.

78. Widal F, Abrami P, Lermoyez J. First complete description of the aspirin idiosyncrasy-asthma-nasal polyposis syndrome (plus urticaria): 1922 (with a note on aspirin desensitization). By F. Widal, P. Abrami, J. Lermoyez. J Asthma 1987;24:297-300.

79. DeGregorio GA, Singer J, Cahill KN, Laidlaw T. A 1-day, 90-minute aspirin challenge and desensitization protocol in aspirin-exacerbated respiratory disease. J Allergy Clin Immunol Pract 2019;7:1174-1180.

80. Kowalski ML, Agache I, Bavbek S, et al. Diagnosis and management of NSAID-Exacerbated Respiratory Disease (N-ERD): a EAACI position paper. Allergy 2019;74:28-39.

81. Stevenson DD, Simon RA. Selection of patients for aspirin desensitization treatment. J Allergy Clin Immunol 2006;118:801804.

82. Woessner KM. Aspirin desensitization for cardiovascular disease. Curr Opin Allergy Clin Immunol 2015;15:314-322.

83. Lee TH, Christie PE. Leukotrienes and aspirin induced asthma. Thorax 1993;48:1189-1190.

84. Cortellini G, Caruso C, Romano A. Aspirin challenge and desensitization: how, when and why. Curr Opin Allergy Clin Immunol 2017;17:247-254.

85. Bianco S, Robuschi M, Petrigni G. Aspirin induced tolerance in aspirin-asthma detected by a new challenge test. IRCS I Med Sci 1977;5:129.

86. Zeiss CR, Lockey RF. Refractory period to aspirin in a patient with aspirin-induced asthma. J Allergy Clin Immunol 1976;57:440-448. 